
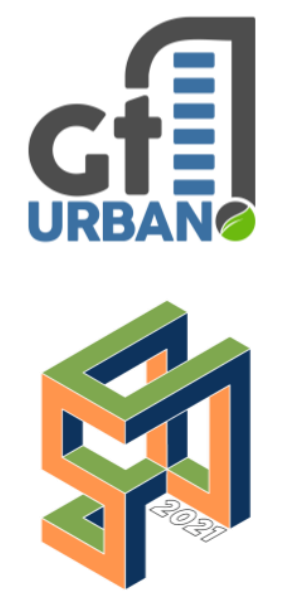

SInGEURB

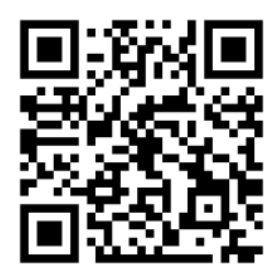

Como citar:

PAULA, Anthony; LEITÃO Camila Tasca; CARDELES Vicenzo Castro. Uma abordagem sobre a dimensão territorial do esgotamento sanitário na região do recreio dos bandeirantes (RJ). In: III SIMPÓSIO NACIONAL DE GESTÃO E ENGENHARIA URBANA: SINGEURB, 2021, Maceió. Anais... Porto Alegre: ANTAC, 2021. p. 471-479. Disponível em: https://eventos.antac. org.br/index.php/sing eurb/issue/view/14

\title{
Uma abordagem sobre a dimensão territorial do esgotamento sanitário na região do Recreio Dos Bandeirantes (RJ)
}

\author{
An approach to the territorial dimension of \\ sanitation in the Recreio Dos Bandeirantes region
} (RJ)

Anthony Paula, Escola Politécnica da UFRJ, anthonycpaula@poli.ufrj.br Camila Tasca Leitão, Escola Politécnica da UFRJ, camilatasca@poli.ufrj.br Vicenzo Castro Cardeles, Escola Politécnica da UFRJ, vicenzocardeles@poli.ufrj.br

\section{RESUMO}

As primeiras construções no bairro do Recreio dos Bandeirantes não contavam com praticamente nenhuma infraestrutura urbana de arruamento, pavimentação, serviços de saúde ou redes de água e esgoto. Nos últimos anos, porém, foram realizadas obras para a implantação de infraestrutura, sendo a rede de esgoto uma das mais recentes e conflituosas. Este artigo visa apresentar características do processo de instalação dos serviços de esgotamento sanitário no bairro do Recreio dos Bandeirantes, e seus conflitos relacionados, envolvendo fatores globais e locais que atuam sobre o território. Tais características foram analisadas através de uma releitura do artigo - A dimensão territorial do esgotamento sanitário: o caso Recreio dos Bandeirantes, Rio de Janeiro, Brasil, (MENDES, T. M. 2010) acrescida de uma pesquisa de campo, através da aplicação de questionários no ano de 2010, que foram aqui atualizados em uma nova atuação no ano de 2020. Além disso, comenta-se o Plano de Saneamento Básico da região buscando analisar as medidas de saneamento adotadas na área.

Palavras-chave: Saneamento, Esgotamento Sanitário, Drenagem Urbana, Recreio dos Bandeirantes.

\begin{abstract}
The first constructions in the neighborhood of Recreio dos Bandeirantes had practically no urban infrastructure for streets, paving, health services or water and sewage networks. In recent years, however, works have been carried out for the implementation of infrastructure, with the sewage network being one of the most recent and conflicting. This article aims to present characteristics of the process of installation of sewage services in the neighborhood of Recreio dos Bandeirantes, and its related conflicts, involving global and local factors that act on the territory. These characteristics were analyzed through a re-reading of the article - The territorial dimension of sewage: the case of Recreio dos Bandeirantes, Rio de Janeiro, Brazil, (MENDES, T. M. 2010) plus field research through the application of questionnaires in the year of 2010, which were updated here in a new application in the year 2020. In addition, the
\end{abstract}


Basic Sanitation Plan of the region is discussed, seeking to analyze the sanitation measures adopted in the area.

Keywords: Sanitation, Sanitary Sewage, Urban Drainage, Recreio dos Bandeirantes.

\section{INTRODUÇÃO}

A região do Recreio dos Bandeirantes assim como diversas regiões do Brasil vem sofrendo um processo de expansão territorial no decorrer das décadas passadas, contudo essa ação na sua grande maioria ocorreu como em outras áreas do Brasil, de uma forma em que o planejamento realizado para que ocorra esse desenvolvimento, tenha cometido erros tanto no planejamento como na execução e fiscalização. Com o passar dos anos a Zona Oeste do Rio de Janeiro, representada nesse artigo pelo Recreio dos Bandeirantes, sofreu e continua sofrendo com áreas ocupadas por construções residenciais, de forma irregular, que não possuem a infraestrutura necessária para serem utilizadas como áreas residenciais. Essa ocupação irregular, aliada a falta de infraestrutura provocou problemas em todas os setores primordiais de uma metrópole (segurança, transporte, educação, hospitalar e saneamento básico entre outras), contudo por meio do saneamento básico pode-se observar a maneira que os danos provocados implicam na rotina da população da região e como o poder público pode auxiliar na melhoria da qualidade de vida dos habitantes.

As obras de adequação das redes de drenagem e de saneamento, que fazem parte do legado Olímpico, estão sendo realizadas na região do Recreio dos Bandeirantes e devem beneficiar a cerca de 80.000 habitantes da região.

O presente artigo tem por objetivo refletir questões pertinentes ao campo do saneamento urbano, realizando uma releitura do artigo - A dimensão territorial do esgotamento sanitário: o caso Recreio dos Bandeirantes, Rio de Janeiro, Brasil. - que foi publicado em 20/05/2016 e teve sua coleta de dados no ano de 2011. Assim primeiramente será analisado o universo de publicações que relacionem estrutura de esgotamento sanitário, saneamento, o levantamento documental da história do bairro do Recreio dos Bandeirantes, no contexto da expansão urbana da cidade e as informações sobre saúde territorial, de modo que, seja realizada uma análise abrangendo acerca do saneamento básico na região. Além disso, será analisada a opinião dos moradores da região do Recreio sobre os avanços desse planejamento desde 2011 a 2020, e se as alternativas impostas pelo plano foram realizadas e se atendem às reais necessidades dos indivíduos.

\section{METODOLOGIA}

A metodologia deste artigo, focou-se inicialmente do estudo de Mendes (2018), foram identificados pontos defasados no período 2018-2020, da área em recorte, que corresponde ao Recreio dos Bandeirantes, bem como em relação ao saneamento básico da região.

Foi identificado defasagens na legislação de 2018 com relação a de 2020, relacionadas ao saneamento básico tendo em vista a criação do Marco legal do Saneamento Básico no ano de 2020 legislação que demandou ser estudada e apresentada de modo a situar o leitor no que o marco legal poderá alterar. Além disso, há um descompasso em relação a situação urbana da região desde 2018 até o momento, devido ao crescimento populacional na região como um todo, a queda de qualidade no serviço de transporte urbano, e do sistema, já irregular, de saneamento básico da região.

Em seguida foi realizada a pesquisa de campo, utilizando o mesmo padrão do questionário de Mendes (2018) distribuído de forma virtual e com as questões atualizadas para o contexto contemporâneo do local, baseados no novo Marco Legal de Saneamento, nas ações de melhoria da Companhia Estadual de Águas e 
Esgotos - CEDAE e nas necessidades dos moradores relatadas nas associações credenciadas da região, com o objetivo de apresentar o resultado atual com as mesmas diretrizes iniciais para realizar uma comparação entre os dois momentos (2010 e 2020).

\section{SITUAÇÃO URBANA ATUAL}

De forma a tornar viável e possível a releitura do artigo realizado em 2011 e publicado em 2016, será necessário primeiramente realizar um trabalho de atualização da legislação vigente para o saneamento básico como sabe-se o Novo Marco Regulatório do Saneamento Básico ou PL4261/2019 (Lei 11.445), para a região a ser estudada, como o objetivo é uma releitura deverá ser analisado a legislação para o Recreio dos Bandeirantes, no Rio de Janeiro quanto ao saneamento e urbanização para verificar quais são as atualizações necessárias.

\subsection{Região Novo Marco Regulatório do Saneamento Básico ou PL4261/2019}

Publicado em 2019 que muda algumas diretrizes para o sistema de saneamento básico brasileiro em diversos pontos como a Agência Nacional de Águas (ANA) instituirá diretrizes de referência para agências reguladoras e prestadoras de serviços de saneamento, os contratos de prestação de serviços de saneamento devem incluir metas de universalização de $99 \%$ de cobertura para abastecimento de água e $90 \%$ de cobertura e tratamento de esgoto até 31 de dezembro de 2033.

Em caso de privatização de empresas estatais de saneamento básico, não existe a necessidade de autorização e aceite por parte dos municípios, caso não haja alterações no objeto e na duração dos seus contratos de programa.

\subsection{Saneamento Básico no Rio de Janeiro em 2020}

Como pode ser visto na Figura 1 abaixo, a questão do saneamento básico assim como do fornecimento de água segue estável nos últimos anos. A situação particular da região estudada mostra diferentes áreas, a maior parte possui elevado poder aquisitivo e consequentemente situações sanitárias melhores, contudo o outro ponto do bairro é composto por áreas de poder aquisitivo aquém a maioria da localidade em que vivem pessoas em condições sanitárias extremas que não usufruem com um saneamento básico eficiente. 
Figura 1: Esquemático do esgotamento Sanitário da Barra da Tijuca, Recreio dos Bandeirantes e Jacarepaguá
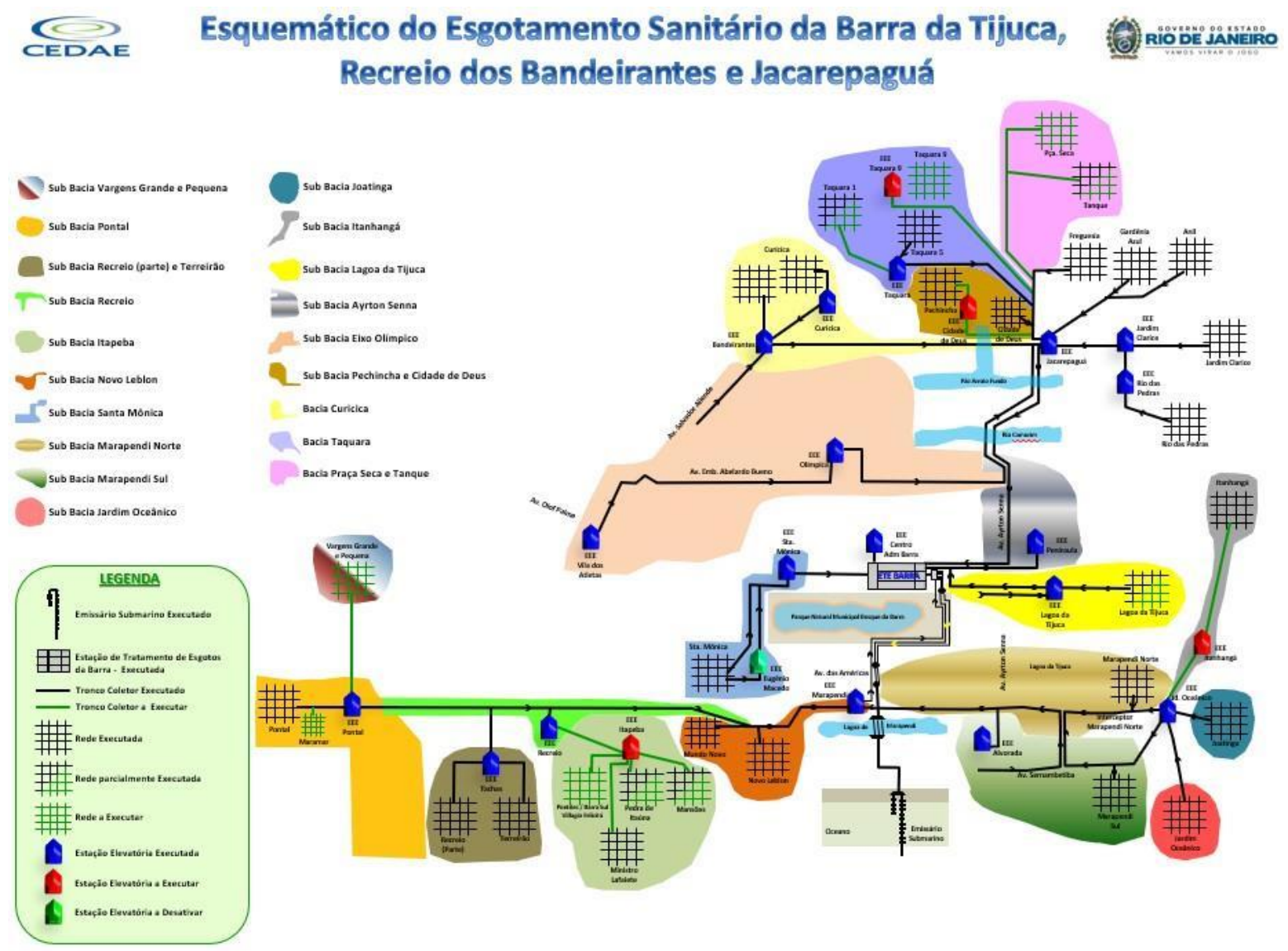

Fonte: CEDAE (2020)

\subsection{Plano de Saneamento Básico Barra da Tijuca, Recreio e Jacarepaguá (PSBJ)}

O PSBJ que teve início em 10 de abril de 2001, com recursos do Fundo Estadual de Conservação Ambiental e Desenvolvimento Urbano - FECAM, sendo executado pela Companhia Estadual de Águas e Esgotos do Rio de Janeiro - CEDAE, implantou um programa cujo objetivo foi de implantar sistemas completos de esgotamento sanitário na Barra da Tijuca, em Jacarepaguá e no Recreio dos Bandeirantes.

Ele está projetado para o horizonte de 30 anos considerando a situação macro de coleta, tratamento e destinação final de 5,3 mil litros por segundo de esgoto, contudo mesmo com esse plano tendo sido iniciado sua implementação em 2001 e planejado para durar por mais de uma década, sua situação é de esgotamento no momento atual. 
Figura 2: Obras executadas do PBSJ

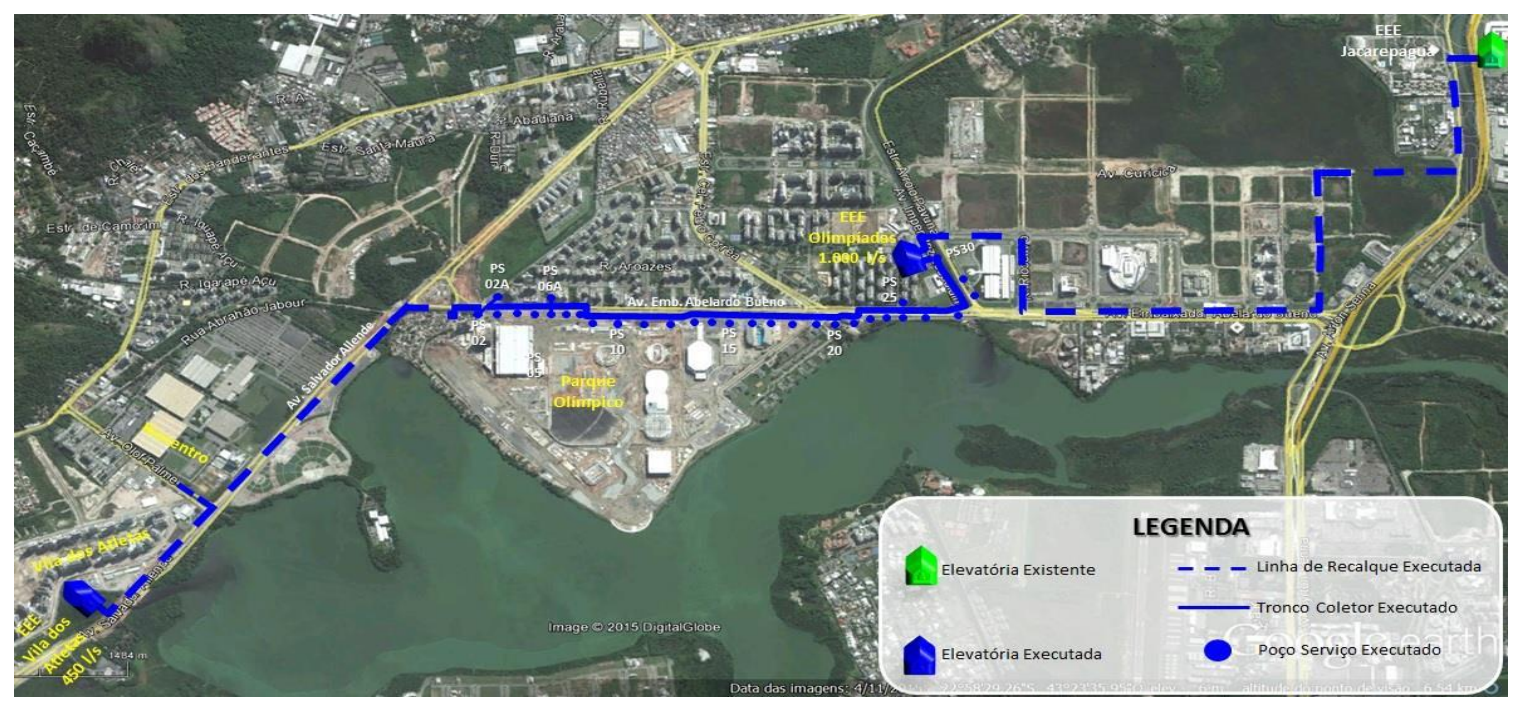

Fonte: CEDAE (2020)

Já na Figura 3 a seguir pode-se ver a planta esquemática das obras que estão em execução no ano de 2020, passados 19 anos, as obras que estão em execução são:

- Modernização dos sistemas de remoção de lodo e escuma com tratamento da superfície interna dos decantadores, Modernização dos sistemas de bombeamento de lodo e escuma com inclusão de trituradores e substituição do cabeamento superior do decantador. $\mathrm{R} \$ 13.948 .547,49$ e Prazo de término em 09/2020;

- Construir o Tronco Coletor, a Estação Elevatória com capacidade de 250 litros por segundo e respectiva Linha de Recalque. $\mathrm{R} \$ 56.854 .995,64$ e $41 \%$ realizada;

- Construir o Tronco Coletor e encaminhar todo o esgoto produzido na Sub-bacia Lagoa da Tijuca para Estação Elevatória de Esgotos Lagoa da Tijuca. R\$25.660.384,18 e 80 \% realizada;

- Coletar e Transportar os esgotos dos empreendimentos a serem construídos pela Luanda e Aparine, assim como, de todo seu entorno, para a Estação Elevatória Jacarepaguá através da implantação de 645 metros de Tronco Coletor. A) Tronco Pedro Correia: Concluído; B) Tronco Leonardo Vilas Boas: Aguardando definição da empresa;

- Implantação de 1.785 metros de Tronco Coletor nos diâmetros de 200 a 500mm, Interligações e Ampliação da Estação Elevatória Santa Mônica. Em execução;

- Implantação de $500 \mathrm{~m}$ de Rede Coletora de Esgotos $\varnothing 250 \mathrm{~mm}, 741 \mathrm{~m}$ Rede de Abastecimento $\varnothing$ $1.200 \mathrm{~mm}$ a $800 \mathrm{~mm}$ e 4 Interligações Prediais. A) Rede Coletora de Esgoto - Executada; B) Rede de Abastecimento de Água - Aguardando definição das empresas. 
Figura 3: Obras a serem executadas do PBSJ

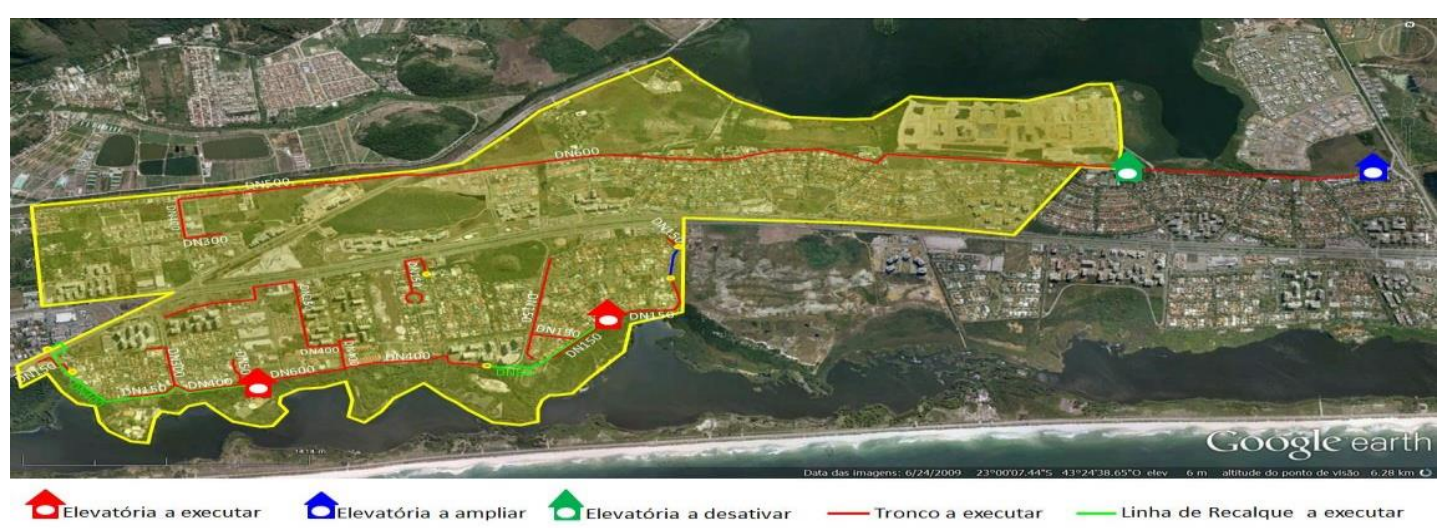

Fonte: CEDAE (2020)

\subsection{Contexto urbano atual}

As regiões do Recreio dos Bandeirantes, Barra da Tijuca e Jacarepaguá durante as últimas décadas sofreram um processo de expansão territorial impulsionado intensamente pelas empresas do setor da construção civil, contudo com o passar dos anos e devido a carência financeira de parte da população carioca a mesma optou por criar residência na região que se deslocava para trabalhar e que ajudou a construir, essa situação se agravou devido as inúmeras crises financeiras que tanto o país como o estado e município do Rio de Janeiro enfrentaram e enfrentam. O crescimento populacional das áreas urbanas em países periféricos traz consigo o desafio de equalizar tal situação capacidade dos Estados de promoverem os serviços necessários à manutenção da qualidade de vida das populações (Hochman, 1998).

Aliado a essa expansão que inicialmente era planejada, houve a ocupação de territórios urbanos que não eram planejados para uso habitacional ou outros usos, o que fez com que tais áreas viessem a sofrer com a falta de saneamento básico, transporte e toda a infraestrutura que deve ser feita antes da habitação ou destinação para outro uso. E com o passar dos anos uma parte dessas áreas veio a se tornar as conhecidas como favelas/comunidades, áreas que tem uma concentração de população que em sua maioria não possui alto poder aquisitivo e vivem em péssimas condições habitacionais.

\section{RESULTADOS E DISCUSSÕES}

\subsection{Pesquisa de campo}

Tendo como referência a pesquisa de campo feita no artigo original, atualizou-se o questionário de forma a considerar as possíveis mudanças e como a população residente no Recreio dos Bandeirantes avalia o saneamento básico na região. Para distribuição desses formulários foram levados em consideração pessoas que morassem na região, tanto na área com valor aquisitivo mais alto quanto as que ocupavam as partes favelizadas do bairro.

A chegada da pandemia da COVID-19 trouxe profundas transformações nos mais diversos espectros da vida cotidiana e o campo de pesquisa não está de fora dessa realidade, por conta disso os questionários foram distribuídos eletronicamente para a Associação de Moradores do Recreio (AMOR) e para Associação 
de Moradores do Canal das Tachas (AMCT), o contato com essas associações foi estabelecido via e-mail e troca de mensagens e informações nas pertinentes as pesquisas nas redes sociais oficiais das organizações.

\subsection{Apuração dos questionários}

Analisando os resultados da pesquisa, observa-se que a carência de serviço de esgoto se encontra entre as três principais problemas que os moradores encontravam no bairro, o respondente poderia assinalar até duas respostas, perdendo apenas violência e iluminação, outro ponto que vale a pena ser considerado é a preocupação com a favelização do bairro cai de 31,4\% em 2010 para 1,2\% em 2020, esse fato pode ser atrelado as medidas de contenção da favelização da região e desapropriação de terrenos pra adequação dos sistemas de transporte e infraestrutura para as Olimpíadas 2016 e a Copa do Mundo de Futebol de 2014.

Nota-se que um aumento na análise da abordagem da mídia com relação aos problemas da região que passou de 8,6\% em 2010 para 15\% em 2020 de respondentes considerando o questionamento como bom e um decréscimo de 14,1\% na avaliação como fraca, o que reflete uma melhora no avanço na divulgação dos problemas. A opinião sobre a infraestrutura de esgotamento existente também subiu de 5,7\% para 9,6\% entrevistados que julgaram como suficiente. Outros resultados da pesquisa podem ser avaliados no Quadro 1 abaixo.

Quadro 1: Resultados dos questionários aplicados na pesquisa campo (em \%)

\begin{tabular}{|l|c|c|}
\hline \multicolumn{3}{|c|}{ Tabela 1. Resultados dos questionários aplicados em campo (em \%) } \\
\hline 1.1: Onde é despejado seu esgoto doméstico? & Amostra 2010 & Amostra 2020 \\
\hline Rede coletora da CEDAE & $60,60 \%$ & $70,00 \%$ \\
\hline Canais, Valões, Rios, Lagoas ou Mar & $21,20 \%$ & $17,50 \%$ \\
\hline Fossa Séptica & $18,20 \%$ & $11,30 \%$ \\
\hline Não possuo ligação de esgoto em casa & $0 \%$ & $1,20 \%$ \\
\hline 1.2: Qual o incômodo causado pelo esgoto do seu bairro? & Amostra 2010 & Amostra 2020 \\
\hline Não me incomoda & $6,70 \%$ & $9,80 \%$ \\
\hline O cheiro me incomoda em casa & $0 \%$ & $19,50 \%$ \\
\hline O cheiro me incomoda quando passo perto de canais & $74,20 \%$ & $65,90 \%$ \\
\hline $\begin{array}{l}\text { O possível contato com a água da chuva me preocupa em épocas } \\
\text { de chuvas }\end{array}$ & $48,40 \%$ & $47,90 \%$ \\
\hline Já tive problemas de saúde, e atribuo os mesmos ao contato com & $3,20 \%$ & $47,60 \%$ \\
\hline Outros & $19,40 \%$ & $14,40 \%$ \\
\hline 1.3: Qual o destino final do seu esgoto doméstico? & Amostra 2010 & Amostra 2020 \\
\hline Lançado em lagoas ou canais & $12,10 \%$ & $20,70 \%$ \\
\hline Lançado no mar & $18,20 \%$ & $7,30 \%$ \\
\hline Infiltrado no solo por canaletas ou fossas & $12,10 \%$ & $6,10 \%$ \\
\hline Não sei & $57,60 \%$ & $56,10 \%$ \\
\hline Outro & $0 \%$ & $9,80 \%$ \\
\hline
\end{tabular}

Fonte: Autores (2020) 


\section{CONCLUSÕES}

Levando em consideração as projeções oficiais do Censo Demográfico de 2010 e as informações da CEDAE a aplicação do Plano de Saneamento Básico Barra da Tijuca, Recreio e Jacarepaguá (PSBJ, 2020) e as avaliações dos moradores da região, as medidas adotadas se mostram inferiores à necessidade dos habitantes, visto que em um período de 10 anos, a percepção dos habitantes ao atual cenário de esgotamento sanitário é de ineficiência e preocupação, a maioria das reclamações relatadas em 2010 se mantiveram ou aumentaram em 2020.

Atenta-se para a necessidade de confirmação das informações dos órgãos competentes referente a rede de coleta existente e a construída, bem como a confirmação de repasse de informações ao público interessado, além disso novos estudos complementares precisam ser feitos para confirmar a atual população do bairro e o planejamento urbano para os próximos anos.

Considerando o acesso ao esgotamento sanitário como uma das condições básicas para melhores condições de saúde, especialmente em áreas urbanas, conclui-se que a região do Recreio dos Bandeirantes essa condição é ineficiente uma vez que o processo de implantação dos sistemas sanitários é incompleto, possuindo ainda instabilidades que são decorrentes das tensões entre Estado e agentes locais, observa-se um crescimento baseado no "espetáculo urbano" (DÉBORD, 1997), em detrimento das estruturas básicas da cidade, tornando a região da Barra da Tijuca e Recreio dos Bandeirantes um exemplo de insustentabilidade socioambiental, apesar de esteticamente bem vista por parte da população.

\section{REFERÊNCIAS}

ANDREAZZI M, BARCELLOS C, HACON S., Velhos indicadores para novos problemas: a relação entre saneamento e saúde. Rev Panam Salud Publica; 22(3):211-217; 2007.

BARCELLOS C., Os Indicadores da Pobreza e a Pobreza dos Indicadores. Uma abordagem geográfica das desigualdades sociais em saúde. In: Barcellos C, organizador. A geografia e o contexto dos problemas de saúde. Rio de Janeiro: Abrasco, ICICT, EPSJV; p. 107-139; 2008.

BRASIL, Lei No 11.445, de 5 de janeiro de 2007. Estabelece diretrizes nacionais para o saneamento básico; altera as Leis nos 6.766, de 19 de dezembro de 1979, 8.036, de 11 de maio de 1990, 8.666, de 21 de junho de 1993, 8.987, de 13 de fevereiro de 1995; revoga a Lei no 6.528, de 11 de maio de 1978; e dá outras providências. Diário Oficial da União 2007; 11 jan.

COSTA, GILBERTO., Novo marco legal do saneamento divide entidades; Disponível em: www.agenciabrasil.ebc.com.br. Projeto de Lei n 4162, de 2019; Disponível em: www25.senado.leg.br; Acessado 2020 Jul 19.

DÉBORD G. A Sociedade do Espetáculo. Rio de Janeiro: Ed. Contraponto; 1997.

HOCHMAN G. A era do saneamento. As bases da política de saúde pública no Brasil. São Paulo: Ed. Hucitec,Anpocs; 1998. 
JULIANO EFGA, FEUERWERKER LCM, COUTINHO SMV, MALHEIROS TF., Racionalidade e saberes para a universalização do saneamento em áreas de vulnerabilidade social. Cien Saude Colet; 17(11):30373046; 2012.

LÜTHI C, MCCONVILLE J, KVARNSTRÖM E., Community-based approaches for addressing the urban sanitation challenges, International Journal of Urban Sustainable Development; 1(1-2):49-63; 2010.

MENDES TM. , A dimensão territorial do esgotamento sanitário:o caso do Recreio dos Bandeirantes, Rio de Janeiro, Brasil - Ciência \& Saúde Coletiva, 23(2):647-658, 2018.

MENDES TM., Informação Sobre Saneamento: a dimensão territorial do esgotamento sanitário no Recreio dos Bandeirantes [dissertação]. Rio de Janeiro: Instituto de Informação e Comunicação em Saúde; 2012.

MINAYO MCS, ASSIS SG, SOUZA ER., Avaliação por triangulação de métodos: abordagem de programas sociais. Rio de Janeiro: Editora Fiocruz; 2005.

PSBJ, Programa de Saneamento da Barra da Tijuca, Recreio dos Bandeirantes e Jacarepaguá; Disponível em https://www.cedae.com.br/saneamento_barra_recreio_jacarepagua; Acessado 2020 Jul 19.

SNIS, Sistema Nacional de Informações sobre Saneamento Disponível em: http://www.snis.gov.br/ ; Acessado 2020 Jul 19.

TEIXEIRA SM, HELLER L, HELLER DGB, OLIVEIRA CAMARGOS E, SILVA PL, REZENDE SC., The participatory process in environmental sanitation issues: how does it reverberate in printed media Journal of Water, Sanitation and Hygiene for Development; 2(1):40-49; 2012. 